\title{
Characterization of Photosynthetic Glycogen and $\alpha$-Glucosidase from Thermophilic Cyanobacteria, Lyngbya-Phormidium-Plectonema Group B
}

\author{
Ken Fujimori, ${ }^{* 1}$ Yotaro Konishi, ${ }^{* 2}$ Noriko Takahashi, ${ }^{* 2}$ \\ and Bhaskaran Muthuvelan*1 \\ ${ }^{*}$ Course of Bioresource Science for Processing, The United Graduate School of Agricultural Sciences, \\ Kagoshima University, Koorimoto, Kagoshima 890, Japan \\ *2Department of Food and Nutrition, Faculty of Human Life Science, Osaka City University, Sugimoto, \\ Sumiyoshi, Osaka 558, Japan
}

(Received January 25, 1995)

We harvested filamentous cyanobacteria from an alkaline hot spring $\left(45-50^{\circ} \mathrm{C}, \mathrm{pH} 8.5-9.0\right)$ in Kagoshima Prefecture, and identified it as Lyngbya-Phormidium-Plectonema (LPP) group B by morphological characteristics. From the TCA-soluble fraction of the LPP group B, we isolated glycogen with average chain length of 11 glucose units. The glycogen showed a similar iodine absorption spectrum to that of rabbit liver glycogen. We also recognized the presence of the TCA-insoluble glycogen at about $48 \%$ of total glycogen, most of which was bound non-covalently to protein and showed similar iodine absorption spectrum to that of the TCA-soluble glycogen. We also found thermophilic and thermostable $\alpha$-glucosidase with optimum pH 6.5 in this cyanobacteria.

Key words: cyanobacteria, Lyngbya-Phormidium-Plectonema group B, glycogen, $\alpha$-glucosidase

Cyanobacteria (blue-green algae), prokaryotic organisms, are commonly found in fresh and salt water. The microalgae already existed over 3 billions years ago, and they have been considered to be responsible for the first significant increase in atmospheric oxygen at that time. Cyanobacteria periodically grow in abundance and sometimes contaminate the water supply, causing harmful effects on wild and domestic animals and man, since some cyanobacteria contain toxins. ${ }^{2)}$ In terms of developing new bioresources, cyanobacteria have attracted much attention due to their high potential for various uses, for example, for food and feed, food additives, fuel, drugs and so on.,3) However, most cyanobacteria, except Spirulina, are underexploited, due to a lack of basic information on their morphological and bio-functional characteristics.

Another interest in cyanobacteria is that they represent a link between bacteria and green plants in evolutionary terms. Therefore, it is of interest to characterize the chemical structure of the polysaccharide produced by oxygenic photosynthesis. Indeed, a high-molecular-weight glucan with both $\alpha-1,4$ and $\alpha-1,6$ glucosidic linkages has been found in cyanobacteria. ${ }^{4,5)}$ The polysaccharide is accumulated with light-dependency ${ }^{6,7)}$ to form granules in the interthylakoidal spaces of vegetative cells..$^{1,5,6,8,9)}$ However, the structure of these polysaccharides has been reported as amylopectin-type ${ }^{(0)}$ or glycogen-like, ${ }^{11)}$ in which average chain length ( $\overline{C L}$ ) varies from 9 to $\left.26 .{ }^{5}\right)$

Recently, we found filamentous non-heterocystous cyanobacteria growing homogeneously in a hot spring (45-50 $\left.{ }^{\circ} \mathrm{C}, \mathrm{pH} 8.5-9.0\right)$ in Kagoshima Prefecture, Japan. We classified it in the Lyngbya-Phormidium-Plectonema
(LPP) group B, Oscillatoriaceae family.

In the present study, as a preliminary step for assessing the LPP group B, we here characterize photosynthetic glycogen as a carbon reserve. In addition, enzymes from the thermophilic cyanobacteria provide the opportunity to investigate the structure and function of protein. This led us to examine the properties of the cyanobacterial $\alpha$ glucosidase, because this enzyme is responsible for glycogen or starch biodegradation in animals, plants, and microorganisms.

\section{Materials and Methods}

\section{Cyanobacteria}

Filamentous cyanobacteria, which formed immotile yellow-green mats about $10 \mathrm{~mm}$ in thickness, were harvested from the thermal gradient of hot spring drainways (45$50^{\circ} \mathrm{C}, \mathrm{pH} 8.5-9.0$ ) located in Tarumizu City, near the volcano Sakurajima, Kagoshima Prefecture, Japan. No contamination of other microorganisms was observed in the sample under light microscopy. The sample was stored at $-30^{\circ} \mathrm{C}$ until use.

\section{Observation of the Cell and Cell Inclusions with Transmis- sion Electron Microscopy}

Bits of filamentous aggregates (approx. 1-2 mm square), obtained from the cyanobacterial mats, were fixed for 4-6 $\mathrm{h}$ at $5^{\circ} \mathrm{C}$, in $2.5 \%(\mathrm{v} / \mathrm{v})$ glutaraldehyde buffered with 0.05 $\mathrm{M}$ cacodylate buffer ( $\mathrm{pH} \mathrm{7.2),} \mathrm{and} \mathrm{dehydrated} \mathrm{through} \mathrm{a}$ graded acetone series. After washing several times in 0.05 $\mathrm{M}$ cacodylate buffer ( $\mathrm{pH} \mathrm{7.2)}$, they were post-fixed in $2 \%$ 
(v/v) $\mathrm{OsO}_{4}$ for $3 \mathrm{~h}$ at $5^{\circ} \mathrm{C}$, followed by dehydration. After embedding in Epon 812, sections were cut on an LKB 11 ultramicrotome with a diamond knife, and then mounted on copper grids. Thin sections stained with $1 \%(\mathrm{w} / \mathrm{v})$ uranylacetate and lead citrate were examined in an HS-12 Hitachi electron microscope.

\section{Isolation of Water-soluble Polysaccharide}

The cyanobacteria ( $20 \mathrm{~g}$ in wet weight) were dispersed in chilled water $(100 \mathrm{~m} l)$ with an Ultra Turrax homogenizer and then cells were ruptured with ultrasonication ${ }^{5)}$ for 60 $\mathrm{min}$. The homogenate was centrifuged $(10,000 \times g, 20 \mathrm{~min})$ and the greenish supernatant was collected, followed by addition of trichloroacetic acid (TCA) to make the final concentration of $4 \%$. By centrifugation $(10,000 \times \mathrm{g}, 20 \mathrm{~min})$, a colorless supernatant and greenish precipitate $(0.26 \mathrm{~g}$ as dry matter) were obtained. From the TCA-soluble fraction, polysaccharide $(0.11 \mathrm{~g})$ was obtained by adding ethanol. On the other hand, since the TCA-insoluble fraction was found to be a mixture of carbohydrates and proteins, it was treated with $\mathrm{NaOH}(0.1 \mathrm{~N})$ at room temperature, or with Actinase E (Waken Co., $1 \mathrm{mg}$ enzyme/ 100 mg sample in $5 \mathrm{ml}$ of $50 \mathrm{mM}$ Tris- $\mathrm{HCl}$ buffer, $\mathrm{pH} \mathrm{7.5)} \mathrm{at}$ $37^{\circ} \mathrm{C}$ for $48 \mathrm{~h}$. The released polysaccharide was precipitated by $66 \%$ ethanol.

\section{Structural Analysis of Polysaccharide}

Iodine absorption spectra of the TCA-soluble and -insoluble polysaccharides were examined by the method of Krisman, ${ }^{12)}$ and compared with various glycogens and starches. For the determination of $\overline{\mathrm{CL}}$ of the polysaccharide, the sample was debranched by isoamylase $(300 \mathrm{U} / 10 \mathrm{mg}$ polysaccharide $/ \mathrm{ml}$ of $60 \mathrm{~mm}$ acetate buffer, $\mathrm{pH} 3.5$ ) at $40^{\circ} \mathrm{C}$ for $24 \mathrm{~h}$ and the ratio of total carbohydrate to reducing power was calculated, as described previously. ${ }^{13)}$ For the determination of $\beta$-amylolysis limit (\%), glycogen or alkali-gelatinized starch was incubated with $\beta$-amylase (40 $\mathrm{U} / \mathrm{mg}$ polysaccharide $/ \mathrm{m} l$ of $0.1 \mathrm{M}$ acatete buffer, $\mathrm{pH} 4.8$ ) at $37^{\circ} \mathrm{C}$ for $6 \mathrm{~h} .{ }^{13)}$ Total carbohydrates were measured by the method of Dubois et al. ${ }^{14)}$ Reducing powers were measured by the method of Somogyi. ${ }^{15}$

\section{Assay for $\alpha$-Glucosidase}

The cyanobacteria were homogenized with 4 volumes of 20 mM Hepes buffer (pH 7.4) containing 0.1 mM EDTA, using an Ultra Turrax homogenizer. The supernatant (crude extract) after centrifugation $(20,000 \times g, 20 \mathrm{~min})$ was used as the source of enzyme. $\alpha$-Glucosidase activity was measured fluorimetrically with 4-methylumbelliferyl- $\alpha$-D-glucoside ( $4 \mathrm{MU} \alpha \mathrm{G}$, Sigma) as substrate at $37^{\circ} \mathrm{C}$, as described previously. ${ }^{16)} \quad \beta$-N-Acetylglucosaminidase activity was measured similarly using 4-methylumbelliferyl- $\beta$ - $\mathrm{N}$-acetylglucosamine (4MU $\beta$ GlcN, Sigma) as substrate. ${ }^{16)}$ The thermostable test for $\alpha$-glucosidase was done as follows. The crude extract was treated at $40-80^{\circ} \mathrm{C}$ for $5 \mathrm{~min}$ and the residual activities were measured at $\mathrm{pH} 6.5$ at $37^{\circ} \mathrm{C} .{ }^{17)}$

\section{Results}

\section{Classification and Ultrastructure of the Thermophilic} Cyanobacteria

Figures 1 and 2 show the ultrastructure of the thin-sec-

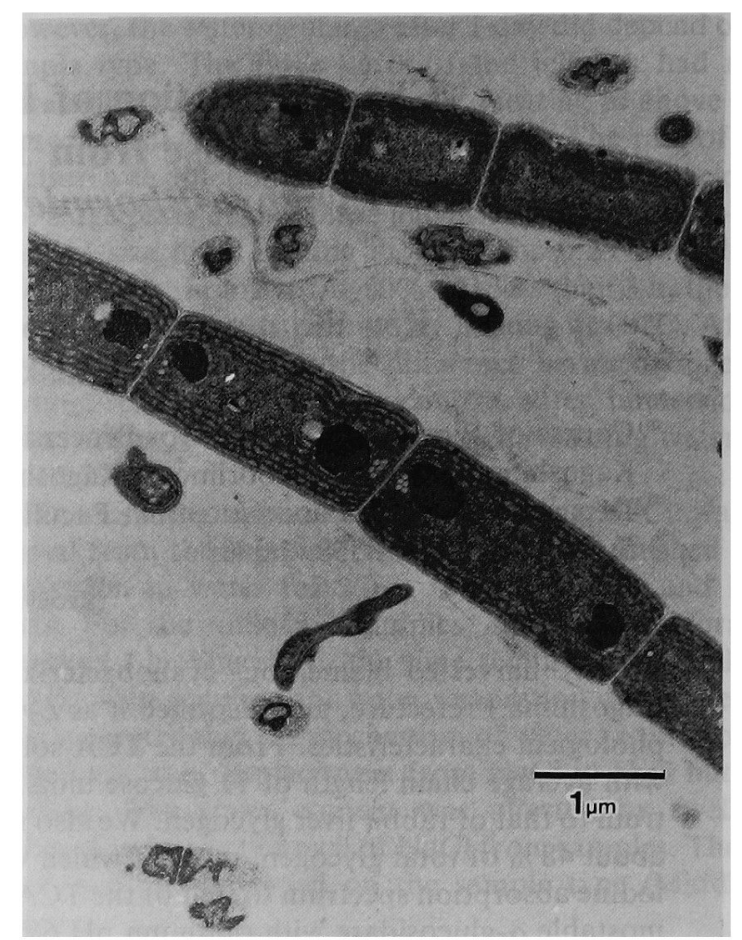

Fig. 1. Electron micrograph of Lyngbya-Phormidium-Plectonema group $B$.

The cyanobacteria were fixed with glutaraldehyde and post-fixed with $\mathrm{OsO}_{4}$. Thin sections were stained with uranylacetate and lead citrate. The straight trichome, the isodiametric or cylindrical cells composing trichome, and the hemispherical terminal cell were observed.

tion of cyanobacteria we obtained. They possessed straight or slightly curved trichome ensheathed, no heterocysts, no endospores or exospores, and shallow constriction (C) between adjacent cells, and reproduce by the intercellular breakage of trichome (Fig. 1). The most conspicuous cytoplasmic elements were the thylakoids (T), which were parallel but separate from one another. The thylakoids are the basic structures for the performance of oxygenic photosynthesis. The cell protoplast was surrounded by a multilayered cell wall, similar to that of Gram-negative bacteria. It consisted of an outer membrane with the unit membrane structure and an electron-opaque peptidoglycan layer (PL) that varied in thickness. This cyanobacteria possessed an additional outer cell layer (sheath, S). The protoplast was limited by a cytoplasmic membrane (CM) of the unit membrane structure (Fig. 2). These characters are commonly related to the genera Lyngbya, Phormidium, and Plectonema. However, further generic assignment was difficult, because these cyanobacteria are greatly influenced by environmental parameters of growth conditions. Therefore, the cyanobacteria used in this study were provisionally placed in broad confines of Lyngbya-Phormidium-Plectonema (LPP) group B in Section III, Oscillatoriaceae family, based on the classification of Rippka et al. ${ }^{18)}$ The nucleoplasm (N) was delimited from the cytoplasm, although there was no nuclear envelope. Other cytoplasmic inclusions like carboxysomes (CA) and ribosomes (R) were detected by electron microscopy (Fig. 2). 




Fig. 2. Ultrastructure of Lyngbya-Phoxmidium-Plectonema group B. C: constriction between adjacent cells, $\mathrm{T}$ : thylakoid, $\mathrm{N}$ : nucleoplasm, CA: carboxysome, S: sheath, R: ribosome, PL: peptidoglycan layer, CM: cytoplasmic membrane.

\section{Fractionation of Water-soluble Polysaccharide}

Table 1 summarizes the fractionation of polysaccharide from LPP group B. From the water-soluble fraction, the yield of the TCA-soluble and -insoluble polysaccharides were $52 \%$ and $48 \%$, respectively. Direct extraction of polysaccharide with TCA decreased in yield, because of coagulation of cells (data not shown). The protein content of the TCA-soluble polysaccharide was $1.3 \%$, by the dye-binding method. ${ }^{19)}$ The carbohydrate:protein ratio $(\mathrm{w} / \mathrm{w})$ of the TCA-insoluble fraction was 1:1.64. The TCA-insoluble carbohydrates were easily solubilized in TCA solution after alkali treatment $(0.1 \mathrm{~N} \mathrm{NaOH})$, with about $80 \%$ recovery. This result suggests that a large amount of the polysaccharide associated with protein is non-covalently attached. A similar result was obtained by treatment of the TCA-insoluble fraction with Actinase E, a proteolytic enzyme (Table 1).

\section{Chemical Property and Structure of the TCA-soluble and -insoluble Polysaccharides}

In a preliminary experiment, we observed that digestion of the TCA-soluble polysaccharide with glucoamylase gave glucose only, which was visualized by the Ag-staining on a paper chromatography (data not shown), suggesting this polysaccharide is $\alpha$-glucan. The iodine absorption spectrum of the polysaccharide was shown to be bimodal
Table 1. Fractionation of water-soluble polysaccharide from LPP group B

\begin{tabular}{|c|c|c|}
\hline \multicolumn{2}{|l|}{ Fraction } & $\begin{array}{l}\text { Polysaccharide } \\
\text { (mg/g wet wt) }\end{array}$ \\
\hline \multirow{2}{*}{\multicolumn{2}{|c|}{$\begin{array}{l}\text { TCA-soluble } \\
\text { TCA-insoluble }\end{array}$}} & 5.4 \\
\hline & & $4.9(100 \%)$ \\
\hline$-+\mathrm{NaOH}$ & TCA-soluble & $3.9(79.6 \%)$ \\
\hline & TCA-insoluble & $1.0(20.4 \%)$ \\
\hline$L+$ Actinas & $\mathrm{E}$ treatment & $3.3(67.3 \%)$ \\
\hline
\end{tabular}

From the water-extract of LPP group B, the TCA-soluble and -insoluble fractions were separated. Polysaccharide in the TCA-soluble fraction was precipitated by ethanol $(66 \%)$. The TCA-insoluble fraction was dried after washing with acetone and ether, This sample was dissolved in $0.1 \mathrm{~N} \mathrm{NaOH}$, followed by separation into the TCA-soluble and -insoluble fractions. The sample was also treated with Actinase E (see Materials and Methods), and the solubilized fraction was collected by centrifugation. Experiment without Actinase $\mathbf{E}$ was simultaneously done as a reference test, in which the amount of carbohydrates released was negligible.

with maximum absorption $\left(\lambda_{\max }\right)$ at $476 \mathrm{~nm}$ (Fig. 3). This profile was similar to that of rabbit liver glycogen $\left(\lambda_{\max }=460 \mathrm{~nm}\right)$, although it was different from that of oyster glycogen or maize phytoglycogen (Fig. 3). The carbohydrate solubilized by alkali or Actinase $\mathrm{E}$ was also found to be glycogen, because it showed a similar iodine absorption spectrum to that of the TCA-soluble glycogen (see Fig. 3).

$\beta$-Amylolysis limit (\%) of the TCA-soluble glycogen of the LPP group B was 37.4 , similar to that of rabbit liver glycogen (38.0) (Table 2). The $\overline{\mathrm{CL}}$ of the glycogen was 11 glucose units, which was similar to that of rabbit liver (Table 2) or Nostoc muscorum ${ }^{8)}$ glycogens, but was different from that of maize amylopectin $(\overline{\mathrm{CL}}=20)$.

\section{Some Properties of $\alpha$-Glucosidase}

$\alpha$-Glucosidase of LPP group B exhibited optimum activity at $\mathrm{pH} 6.5$ (Fig. 4). A similar profile of $\mathrm{pH}$-activity curve was obtained on $\beta$-N-acetylglucosaminidase, which is a lysosomal marker enzyme in mammalian tissues. The $\alpha$ glucosidase of LPP group B was thermophilic and thermostable. The temperature giving the maximum activity was $65^{\circ} \mathrm{C}$, at which the initial velocity was about 7 times higher than that at $37^{\circ} \mathrm{C}$ (data not shown). As shown in Table 3, the temperature giving 50\% residual activity was $67^{\circ} \mathrm{C}$, which was higher than that of the enzyme from masu salmon liver $\left(47^{\circ} \mathrm{C}\right)$, mouse liver $\left(53^{\circ} \mathrm{C}\right)$, or banana pulp $\left(52^{\circ} \mathrm{C}\right) .^{17)}$

\section{Discussion}

The present study shows first that the LPP group B contains photosynthetic glycogen, similar to animal glycogen in structure. Photosynthetic glycogen has also been found in Chromatium, a purple sulfur bacterium, which is of a lower order than cyanobacteria. ${ }^{20)}$ In addition, glycogenlike polysaccharide has been found in Cyanodium, which is supposed to be a primitive eukaryotic alga, phylogenically between cyanobacteria and red algae. ${ }^{21)}$ Thus, glycogen is a primordial carbon reserve through an evolutional process. In addition, the properties of glycogen synthase and branching enzyme are considered to be conservative in evolutionary progression, although ADP-glucose serves as a glucosyl donor in cyanobacteria, ${ }^{22)}$ as in bacteria and 


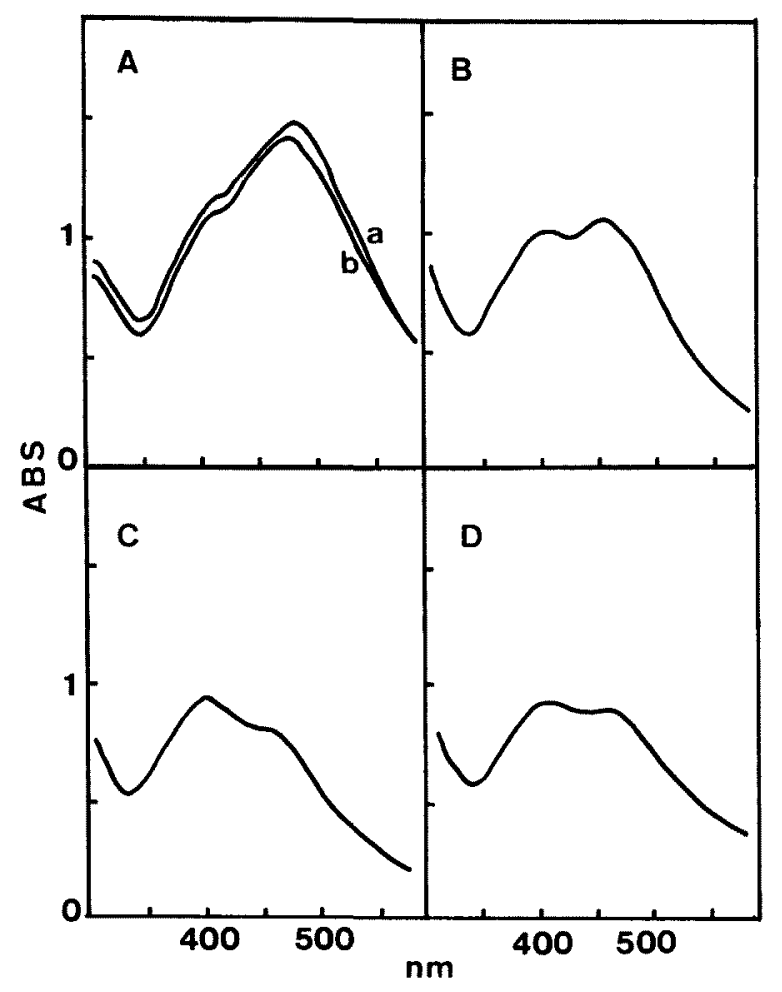

Fig. 3. Iodine spectra of various glycogens.

The absorption spectra of iodine-glycogen complexes were measured. (A) The TCA-soluble (a) and the TCA-insoluble (b) glycogen of the LPP group B, (B) Rabbit liver glycogen, (C) Oyster glycogen, (D) Sugary maize phytoglycogen.

green plants, while UDP-glucose serves as such in animals.

It is noteworthy that a large amount of glycogen with proteins of LPP group B was precipitated by TCA, although its biological significance is unknown. Since many proteins could be removed by the treatment with alkali or Actinase E, they would adsorb on the surface of glycogen granules and would include glycogen-metabolizing enzymes. ${ }^{23)}$ The trace amount of protein $(1.3 \%)$ found in the TCA-soluble glycogen would not be artificial. It is recognized that glycogen is associated with protein and is referred to as a proteoglycan. ${ }^{23)}$ For the protein that was covalently bound to glycogen, one can recall glycogenin in animal tissues, which is responsible for glycogen biosynthesis de novo. ${ }^{24,25)}$ However, it is unknown whether glycogenin or its analogous protein is related to the biosynthesis of glycogen in cyanobacteria.

Table 2. Average chain lengths ( $\overline{\mathrm{CL}} \mathrm{s})$ and $\beta$-amylolysis limits (\%) of glycogen and starch

\begin{tabular}{lcc}
\hline$\alpha$-Glucans & $\overline{\mathrm{CL}}$ & $\begin{array}{c}\beta \text {-amylolysis } \\
\text { limit (\%) }\end{array}$ \\
\hline LPP group B TCA-soluble glycogen & 11 & 37.4 \\
LPP group B TCA-insoluble glycogen & 11 & N.D. \\
Oyster glycogen & 8 & 40.6 \\
Rabbit liver glycogen & 10 & 38.0 \\
Potato amylopectin & 24 & N.D. \\
Maize amylopectin & 20 & 65.0 \\
\hline
\end{tabular}

N.D., not determined.

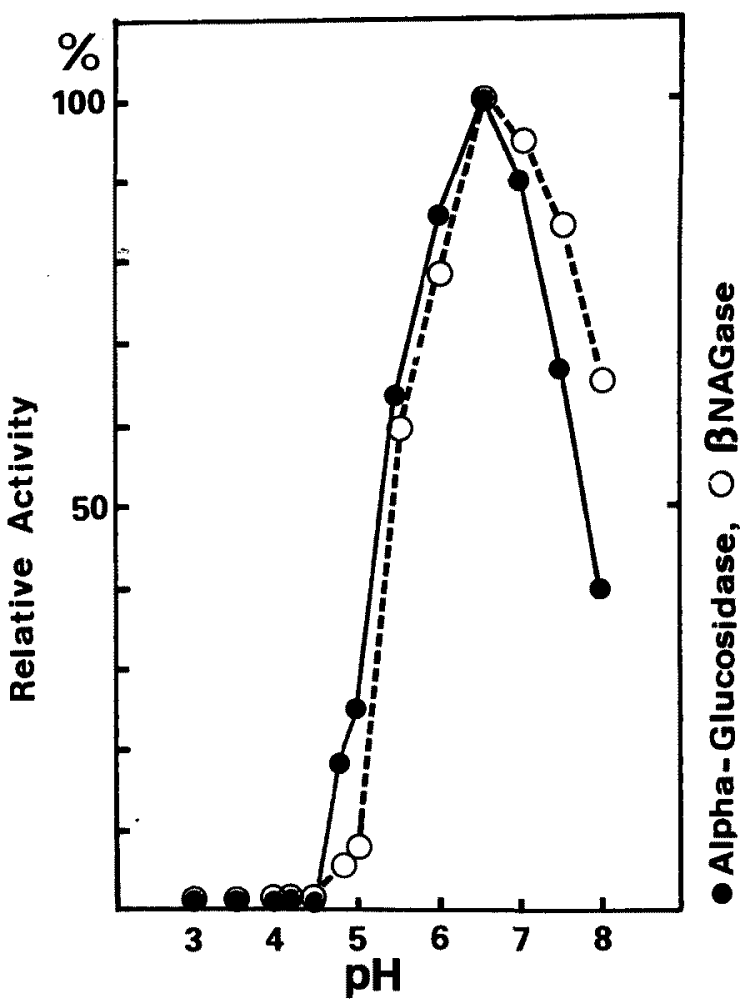

Fig. 4. pH-Activity curves of $\alpha$-glucosidase and $\beta$ - $\mathrm{N}$-acetylglucosaminidase of Lyngbya-Phormidium-Plectonema group B.

The LPP group B crude extract (see Materials and Methods) was used as the source of enzymes. $\alpha$-Glucosidase and $\beta$-N-acetylglucosaminidase activities were measured fluorimetrically using $4 \mathrm{MU} \alpha \mathrm{G}$ and $4 \mathrm{MU} \beta \mathrm{GIcN}$, respectively, as substrates.

The present study also provides basic information on $\alpha$-glucosidase, since there have been few studies on this enzyme. In general, eukaryotic cells contain two $\alpha$-glucosidase isozymes, acid and neutral $\alpha$-glucosidases with optimum pHs of $4-5$ and 6-7, respectively. The former is present in lysosomes and the latter in microsomes or cytoplasm. The findings in the present study that the $\alpha$ glucosidase of LPP group B had optimum pH 6.5 are likely to be related to the fact that the prokaryote lacks lysosomes. $\alpha$-Glucosidases purified from various bacteria have also been known to have optimum $\mathrm{pH}$ 6-7.26) In addition, the $\alpha$-glucosidase of LPP group B was thermophilic and thermostable. These properties have been reported in thermophilic bacterium, Bacillus thermoglucosidius, ${ }^{20}$ or archaebacterium Pyrococcus furiosus. ${ }^{27}$. From a phys-

Table 3. Comparison of thermostabilities of various source of $\alpha$ glucosidases

\begin{tabular}{lc}
\hline \hline Enzyme source $*_{1}$ & Temperature $\left({ }^{\circ} \mathrm{C}\right)^{*_{2}}$ \\
\hline Masu salmon liver & 47 \\
Mouse liver & 53 \\
Banana pulp*3 & 52 \\
LPP group B & 67 \\
\hline
\end{tabular}

* Crude extract treated for 5 min at $37-80^{\circ} \mathrm{C}$.

$*_{2}$ Temperature $\left({ }^{\circ} \mathrm{C}\right)$ giving $50 \%$ residual activity at $\mathrm{pH} 6.5$.

${ }^{* 3}$ See reference of (17). 
iological aspect, $\alpha$-glucosidase, together with other $\alpha$ amylolytic enzymes, could be one of the most important enzymes to form glucose as an energy supply. However, it is unknown whether $\alpha$-amylolytic or phosphorolytic degradation of glycogen is a major pathway in cyanobacteria. For the utilization of the LPP group $B$, the thermoresistant $\alpha$-glucosidase might be useful for saccharification of starch. To obtain the bulk enzyme, mass-culture of the cyanobacteria is required, although this has not been achieved yet.

Acknowledgments We are grateful to Dr. K. Ohki, School of Marine Science and Technology, Tokai University, for valuable advice and to Mr. K. Kawashima (Yomei Hot Spring), Mr. Y. Tsuruta (Tarumizu Hot Spring Tsuruta) for the generous supply of cyanobacteria. We also thank Ms. K. Takenouchi and $\mathbf{H}$. Kawauchi for collecting specimens.

\section{References}

1) P. Fey: The Blue-Greens, Edward Arnold Ltd., London, 1983.

2) W. W. Carmichael: The toxins of cyanobacteria. Scientific American, 242, 78-86, (1994).

3) K. Yamaguchi: Present situation and future directions, in "Utilization of Microalgae" (ed. by K. Yamaguchi), Koseisha-Koseikaku, Tokyo, 1992, pp. 9-17 (in Japanese).

4) G. E. Fogg: The comparative physiology and biochemistry of the blue-green algae. Bacteriol. Rev., 20, 148-165 (1956).

5) J. M. Shively: Inclusions: Granules of polyglucose, polyphosphate, and poly- $\beta$-hydroxybutyrate. Method Enzymol., 167, 195-203 (1988).

6) L. L. Richardson and R. W. Castenholz: Enhanced survival of the cyanobacterium Oscillatoria terebriformis in darkness under anaerobic conditions. Appl. Environ. Microbiol., 53, 2151-2158 (1987).

7) T. A. Sarma and S. Kanta: Biochemical studies on sporulation in blue-green algae. Z. Allgemeine Microbiol., 19, 571-575 (1979).

8) L. Chao and C. C. Bowen: Purification and properties of glycogen isolated from a blue-green alga, Nostoc muscorum. J. Bacteriol., 105, 331-338 (1971).

9) T. E. Jensen: Cyanobacterial cell inclusions of irregular occurrence: systematic and evolutionary implications. Cytobios, 39, 35-62 (1984).

10) L. Hough, J. K. N. Jones, and W. H. Wadman: An investigation of the polysaccharide components of certain fresh-water algae. $J$. Chem. Soc., 152, 3393-3399 (1952).

11) J. F. Fredrick: Preliminary studies on the synthesis of polysaccharides in the algae. Physiol. Plantarum, 4, 621-626 (1951).

12) C. R. Krisman: A method for the colorimetric estimation of glyco- gen with iodine. Anal. Biochem, 4, 17-23 (1962).

13) $Y$. Konishi and $H$. Fuwa: Structural changes in rat liver glycogen during refeeding after fasting. Agric. Biol. Chem., 47, 1049-1056 (1983).

14) M. Dubois, K. A. Gilles, J. K. Hamilton, P. A. Roberts, and F. Smith: Colorimetric method for determination of sugars and related substances. Anal. Chem., 28, 350-356 (1956).

15) M. Somogyi: Note on sugar determination. J. Biol. Chem., 195, 19-23 (1952).

16) Y. Konishi, Y. Okawa, S. Hosokawa, K. Fujimori, and H. Fuwa: Lysosomal glycogen accumulation in rat liver and its in vivo kinetics after a single intraperitoneal injection of acarbose, an $\alpha$-glucosidase inhibitor. J. Biochem., 107, 197-201 (1990).

17) Y. Konishi, S. Kitazato, and N. Nakatani: Partial purification and characterization of acid and neutral $\alpha$-glucosidases form preclimacteric banana pulp tissues. Biosci. Biotech. Biochem., 56, 2046-2051 (1992).

18) R. Rippka, J. Deruelles, J. B. Waterbury, M. Herdman, and R. Y. Stanier: Generic assignments, strain histories and properties of pure cultures of cyanobacteria. J. Gen. Microbiol, 110, 1-61 (1979).

19) S. M. Read and D. H. Northcote: Minimization of variation in the response to different proteins of the Coomassie Blue $\mathrm{G}$ dye-binding assay for protein. Anal. Biochem., 116, 53-64 (1981).

20) F. Hara, T. Akazawa, and K. Kojima: Glycogen biosynthesis in Chromatium strain D. I. Characterization of glycogen. Plant Cell Physiol., 14, 737-745 (1973).

21) J. F. Fredrick and J. Seckbach: Intraspecies evolution of enzymic mechanisms associated with the synthesis of $\alpha-1,4$ storage glucans in two thermophilic-acidophilic algae of Cyanidium type. Phytochemistry, 22, 1155-1157 (1983).

22) A. A. Igresias, G. Kakefuda, and J. Preiss: Regulatory and structural properties of the cyanobacterial ADP-glucose pyrophosphorylases. Plant Physiol., 97, $1187-1195$ (1991).

23) P. C. Calder: Glycogen structure and biogenesis. Int. J. Biochem., 23, 1335-1352 (1991).

24) J. Pitcher, C. Smythe, D. G. Campbell, and P. Cohen: Identification of the $38-\mathrm{kDa}$ subunit of rabbit skeletal muscle glycogen synthase as glycogenin. Eur. J. Biochem., 169, 497-502 (1987).

25) J. Lomako, W. M. Lomako, and W. J. Whelan: A self-glucosylating protein is the primer for rabbit muscle glycogen biosynthesis. FASEB J., 2, 3097-3103 (1988).

26) Y. Suzuki, T. Yuki, T. Kishigami, and S. Abe: Purification and properties of extracellular $\alpha$-glucosidase of a thermophile, Bacillus thermoglucosidius KP1006, Biochim. Biophys. Acta, 445, 386-397 (1976).

27) H. R. Costantino, S. H. Brown, and R. M. Kelly: Purification and characterization of an $\alpha$-glucosidase from a hyperthermophilic archaebacterium, Pyrococcus furiosus, exhibiting a temperature optimum of 105 to $115^{\circ} \mathrm{C}$. J. Bacteriol., 172, 3654-3660 (1990). 